\title{
Accidental Inferior Turbinectomy with Airway Obstruction during Nasal Intubation
}

\author{
${ }^{1}$ Ankitha Sunand, ${ }^{2}$ Chikkegowda Sangeetha, ${ }^{3}$ Pawan, ${ }^{4}$ Hiremathada Sahajananda
}

\begin{abstract}
Synchronous tumors of different histological types involving the salivary gland are rare. There have been cases reported in the literature of such tumors occurring in the parotid gland. Head and neck surgeons frequently request nasotracheal intubation for their surgical procedures. Complications of nasal intubation include epistaxis, sinusitis, bacteremia, or dislodgement of adenoids from trauma of the intubation.

We describe a case report of accidental removal of the inferior turbinate with nearly complete airway obstruction, during nasotracheal intubation. This case report demonstrates the importance of early detection and management of this potentially dangerous complication.
\end{abstract}

Keywords: Nasal intubation, Pleomorphic adenoma, Ring adair elwyn endotracheal tube, Turbinectomy.

How to cite this article: Sunand A, Sangeetha C, Pawan, Sahajananda $\mathrm{H}$. Accidental Inferior Turbinectomy with Airway Obstruction during Nasal Intubation. J Med Sci 2018;4(1):14-16.

Source of support: Nil

Conflict of interest: None

\section{INTRODUCTION}

Salivary gland neoplasms are uncommon. They represent only 2 to $3 \%$ of the head and neck tumors. Salivary gland tumors of different histological types in a single gland are rare. They constitute less than $0.3 \%$ of all salivary gland neoplasms. ${ }^{1,2}$ The most common benign salivary gland neoplasm is a pleomorphic adenoma or a benign mixed tumor, ${ }^{3}$ with a $50 \%$ incidence in the submandibular gland. The most common dual pathology reported is a Warthin's tumor with a pleomorphic adenoma. ${ }^{4,5}$ There have been cases reported in the literature of a benign and a malignant tumor in the same gland, especially in the parotid gland..$^{1-6}$

Here, we report a case of a 62-year-old male who presented with left submandibular gland pleomorphic

${ }^{1}$ Resident, ${ }^{2}$ Assistant Professor, ${ }^{3}$ Associate Professor, ${ }^{4}$ Professor and Head

${ }^{1-4}$ Department of Anesthesiology, RajaRajeswari Medical College \& Hospital, Bengaluru, Karnataka, India

Corresponding Author: Chikkegowda Sangeetha, Assistant Professor, Department of Anesthesiology, RajaRajeswari Medical College \& Hospital, Bengaluru, Karnataka, India, Phone: +919886623479, e-mail: sanguidaya.sd@gmail.com adenoma posted for left submandibular gland excision and selective neck dissection and platysma flap reconstruction of floor of mouth on the left side. The diagnosis in this case was made following a complete surgical excision of the gland, which was the surgical treatment modality for the tumor. In this report, we describe accidental removal of the middle turbinate during intubation and how it resulted in the near-complete respiratory obstruction.

\section{CASE REPORT}

A 62-year-old male patient was presented to the outpatient department of our hospital with a 6 months history of swelling in the left submandibular region. The swelling, insidious on onset and slowly progressive in nature, was associated with pain since 1 week with no discharge. There was no increase in size of the swelling with intake of food, also there was no difficulty in swallowing. No change of voice or difficulty in breathing was noticed. $\mathrm{He}$ also gave a history of 30 years of smoking and consumption of alcohol, and is a known case of diabetes mellitus and since 3 years was on tablet Metformin (500 mg). He had no other comorbid illnesses.

On examination of the oral cavity, an ulceroproliferative growth of $4 \times 3 \mathrm{~cm}$ was noticed over left side of floor of mouth lateral to frenulum and covering the sublingual gland. It extended anteriorly from left lower lateral incisor up to first premolar. It had reddish appearance and growth was free from alveolar surface. Neck examination showed a well-defined, hard oval-shaped swelling of size $2 \times 1.5 \mathrm{~cm}$ present just below the left side of the mandible. The skin over the swelling was normal with no visible pulsations, and nontender skin over swelling was movable. There were no other swellings, and no lymph nodes were palpable. With the suspicion of a chronic submandibular sialadenitis, further investigations were conducted.

On examination, his pulse rate was found to be 84 / minute (regular) and blood pressure (BP) was 126/ $80 \mathrm{~mm} \mathrm{Hg}$. Respiratory and cardiovascular systems were normal. Laboratory investigations were found normal, and serological investigations were also normal. A 12-lead electrocardiogram (ECG) showed $\mathrm{T}$ wave inversion in $\mathrm{v} 1$ to v3 leads.

Contrast-enhanced computed tomography (CECT) neck showed $4 \times 2 \times 3.6 \mathrm{~cm}$ ill-defined lesion in left of the 
floor of mouth with left submandibular nodes measuring $1 \times 1 \mathrm{~cm}$. Fine-needle aspiration cytology report showed features of pleomorphic adenoma. The CECT of abdomen showed old healed abscess in liver.

Patient was scheduled for left submandibular gland excision and selective neck dissection and platysma flap reconstruction of floor of mouth on the left side. Patient was counselled for the proposed anesthesia procedure, and informed consent was obtained. In the operating room, all the physiological monitors were connected. Monitoring included ECG, pulse oximetry $\left(\mathrm{SpO}_{2}\right)$, temperature, and noninvasive BP. His baseline vitals were heart rate of 84 beats/minute, $\mathrm{BP}$ of $128 / 90 \mathrm{~mm} \mathrm{Hg}$, and $\mathrm{SpO}_{2}$ of $100 \%$. The patient was premedicated with injection Glycopyrrolate [0.2 mg intravenous (IV)] and injection midazolam (1 mg IV), and preoxygenated with $10 \mathrm{~L}$ of $100 \%$ oxygen for 5 minutes. Nasal vasoconstrictor drops were applied into both nostrils. The patient was induced with injection propofol (100 mg IV) at 9:50 am, and afterward injection Vecuronium (5 mg IV). He was intubated successfully nasally with a lubricated north pole ring adair elwyn (RAE) tube of $7.5 \mathrm{~mm}$ with the bevel facing medially in first attempt under direct vision. On auscultation, there was diminished/absent breath sounds. There was no chest raise when the patient was put on mechanical ventilator, but minimal chest raise was seen when positive-pressure ventilation was applied using Ambu bag. It also showed slight resistance. We continued hand ventilating as $\mathrm{ETCO}_{2}$ showed waveforms on the monitor. Since there was no adequate chest raise, woody chest was suspected, and immediately injection deriphyllin (84.7 mg, $2 \mathrm{~mL}$, slow IV) was given, and injection $\mathrm{MgSO}_{4}$ (2 gm IV) was administered twice. Additionally, injection hydrocortisone (100 mg) as well as injection Dexona (8 mg) were given. Arterial blood gas (ABG) analysis was done and it showed $\mathrm{PaO}_{2}$ of $110 \mathrm{mmHg}$ and $\mathrm{PaCO}_{2}$ of $65 \mathrm{~mm} \mathrm{Hg}$.

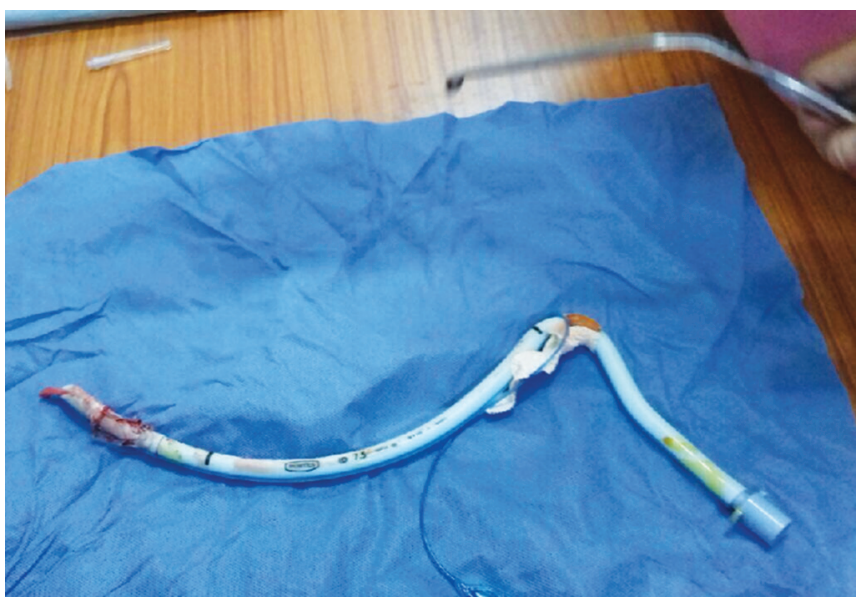

Fig. 1: Sheared inferior turbinate in the bevel end of the north pole RAE endotracheal tube
The $\mathrm{ETCO}_{2}$ monitor showed values between 70 and 75 . Despite all these measures, as there was no improvement; immediately the decision was taken to extubate the patient as $\mathrm{PaCO}_{2}$ was building up. At 10:30 AM, patient was extubated. After extubation, it was observed that RAE tube tip was blocked by inferior turbinate (Figs 1 and 2), which measured around $4 \mathrm{~cm}$ in length. Only 1 to $2 \mathrm{~mm}$ space was left in the RAE tube to ventilate the patient. Immediately, patient was reintubated orally using $7.5 \mathrm{~mm}$ cuffed endotracheal tube with the help of bougie at 10:32 AM, and bilateral air entry was present and chest raise was adequate. At 10:50 am, ABG was repeated and it showed $\mathrm{PaO}_{2}$ of $120 \mathrm{~mm} \mathrm{Hg}$ and $\mathrm{PaCO}_{2}$ of $32 \mathrm{~mm} \mathrm{Hg}$. $\mathrm{PaO}_{2}$ and $\mathrm{SpO}_{2}$ was maintained throughout the procedure. General anesthesia was maintained with oxygen + sevoflurane + intermittent doses of vecuronium. Multimodal analgesia was administered using injection paracetamol (1 gm IV) and injection pethidine (10 mg IV). Following completion of surgery, patient was shifted to the intensive care unit and electively ventilated overnight, and the next day morning patient was reversed with injection myopyrolate $(0.5 \mathrm{mg}$ of Glycopyrrolate and $2.5 \mathrm{mg}$ of neostigmine). The patient was extubated after he was awake with adequate muscular tone and power. The patient emerged from anesthesia uneventfully and experienced an uncomplicated postoperative course. The patient was stable and further course was uneventful, and so discharged the next day. The patient was placed on antibiotics for 5 days, and nasal vasoconstrictor drops and saline sprays for 1 week. He suffered no further complications.

\section{DISCUSSION}

During nasal intubation, the inferior turbinate is at greater risk of trauma than is the middle turbinate, because it is closer to the nasotracheal tube. ${ }^{7}$ Preexisting intranasal abnormalities, such as an enlarged inferior

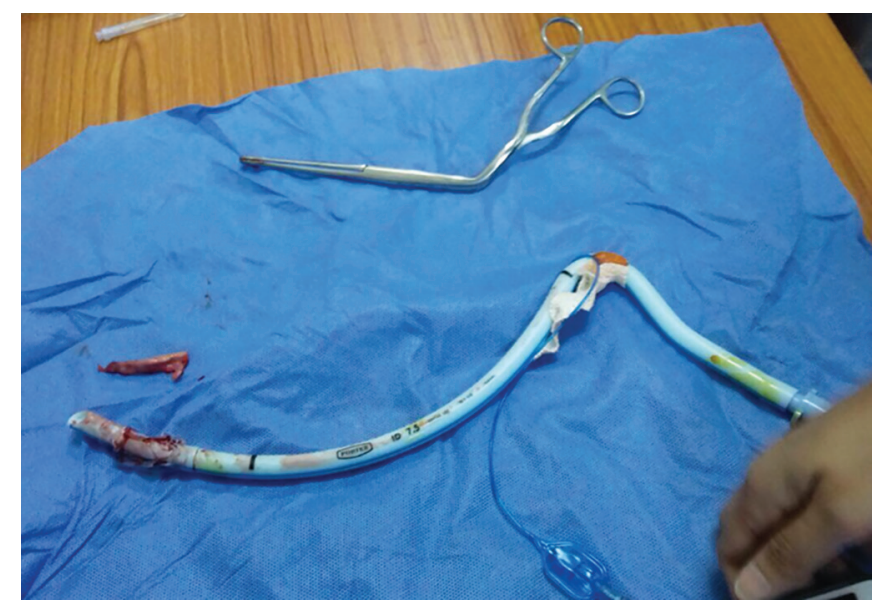

Fig. 2: Inferior turbinate which measured around 3.5 to $4 \mathrm{~cm}$, and north pole RAE tube which was used for this patient 
turbinate or a septal spur, increase the risk of middle turbinate trauma when they cause the nasotracheal tube to be redirected higher into the nasal cavity. Also, trauma to the middle turbinate can still occur in the presence of normal anatomy. The body of the middle turbinate is integrated into the ethmoid air system. As it descends anteriorly, it attaches to cribriform plate; posteriorly, it is anchored loosely into the ethmoidal air cells. Applying excessive force to the middle turbinate can cause a fracture to the floor of the anterior cranial fossa and result in cerebrospinal fluid leak. ${ }^{8}$ The trauma to the inferior turbinate is rare, but it did occur in our case. The tube was $98 \%$ blocked by the inferior turbinate, which was snugly fitted and there was a very tiny gap which allowed the oxygenation to be sustained for a while. Hence, we experienced the resistance to ventilation and inadequate chest rise. Later, carbon dioxide build-up showed inadequate ventilation. There is a saying in our anesthesia practice: "when in doubt take it out." We also followed the same philosophy.

Moore ${ }^{9}$ suggested a technique for nasotracheal intubation that prevents damage to the turbinates. The nose was adequately decongested prior to intubation, and lubrication was applied to the tube. Intubation was performed with cephalad traction on the tube and with the bevel directed laterally so that its leading edge is pointed away from the turbinates. As soon as the tip of the tube is visualized in the oropharynx, the part of the tube outside the nostril is returned to its normal curvature and advanced toward the larynx. ${ }^{9}$

The feeding vessels to the middle turbinate branch originate in the proximal portion of the posterior lateral nasal artery just after it exits the sphenopalatine foramen. ${ }^{10}$ We assume that the middle turbinate in our patient survived on this branch of the sphenopalatine artery via a pedunculated stalk. This case serves as a reminder of the life-threatening hazards of nasotracheal intubation. Oral intubation may be a reasonable alternative to nasal intubation in patients whose general hygiene and health care are less than optimal. If it is mandatory, we should try and follow Moore's technique.

\section{REFERENCES}

1. Curry JL, Petruzelli GJ, McClatchey KD, Lingen MW. Synchronous benign and malignant salivary gland tumors in ipsilateral glands: a report of two cases and a review of literature. Head Neck 2002 Mar;24(3):301-306.

2. Gnepp DR, Schroeder W, Heffner D. Synchronous tumours arising in a single major salivary gland. Cancer 1989 Mar;63(6):1219-1224.

3. Misselevich I, Podoshin L, Fradish M, Boss JH. Salivary gland double tumor: synchronous ipsilateral pleomorphic adenoma and acinic cell carcinoma of the parotid gland. Ann Otol Rhinol Laryngol 1997 Mar;106(3):226-229.

4. Tanaka S, Tabuchi K, Oikawa K, Kohanawa R, Okubo H, Ikebe D, Noguchi M, Hara A. Synchronous unilateral parotid gland neoplasms of three different histological types. Auris Nasus Larynx 2007 Jun;34(2):263-266.

5. Stavirianos SD, McLean NR, Soames JV. Synchronous unilateral parotid neoplasms of different histological types. Eur J Surg Oncol 1999 Jun;25(3):331-332.

6. Herce-Lopez J, Salazar-Fernandez CI, Mayorga-Jimenez F, Gallana-Alvarez S, Pérez-Sánchez JM. Synchronous unilateral parotid neoplasms. A case report. Med Oral Patol Oral Cir Bucal 2009 Feb;14(2):E90-E92.

7. Stankiewicz JA. Advanced endoscopicsinus surgery. St. Louis (MO): Mosby; 1995.p. 2.

8. Wigand ME. Endoscopic surgery of the paranasal sinuses and anterior skull base. New York: Thieme; 1990. pp. 25-26.

9. Moore DC. Bloodless turbinectomy following blind nasal intubation: faulty technique? Anesthesiology 1990 Nov;73(5):1057.

10. Lee HY, Kim HU, Kim SS, Son EJ, Kim JW, Cho NH, Kim KS, Lee JG, Chung IH, Yoon JH. Surgical anatoy of the sphenopalatine artery in the lateral nasal wall. Laryngoscope 2002 Oct;112(10):1813-1818. 